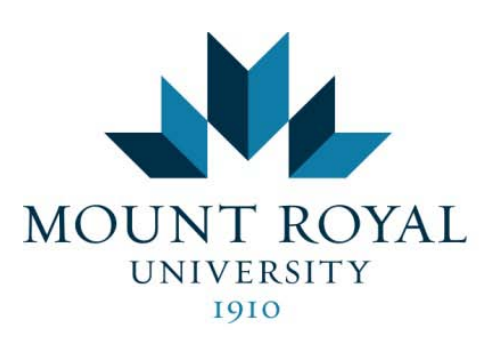

Mount Royal Undergraduate Education Review
Department of Education and Schooling

Volume 1(2)

Fall 2014

\title{
Inquiry into the use of digital technology in elementary music education
}

Kirsten Kerslake, Mount Royal University

Link to Digital Story

\begin{abstract}
Music education is an important part of a child's elementary education. There are many types of new digital technologies that are appearing in our schools. Through inquiry research and the use of an online survey, in-person and email interviews, I have attempted to discover what digital programs or tools are out there to assist with learning the various musical concepts in elementary music curriculum, as well as how digital technology in music curriculum is used to keep the children engaged in their learning. The findings led me to a conclusion that people believe that music education at an elementary level is important, has both pros and cons, and must be used in correspondence with traditional teaching methods. Digital technology can be beneficial in music education if the teacher understands how to use it properly to promote active and engaged student learning.
\end{abstract}




\section{Introduction}

Music is a fun and easy way to engage children’s learning. It can also cause frustration and confusion when learning the more difficult musical concepts within music curricula. Music has been an extremely important and central part of my life since elementary school. I had amazingly talented music specialists throughout my schooling who have fostered a passion and love for music and music education. I have used a couple digital technologies while learning music in elementary school, but it was such a new thing still when I was in elementary school. I remember it being a creative and fun way to understand musical concepts that were part of our curriculum. Throughout my university volunteer experience I was also given the opportunity to have a classroom placement in a grade 2-6 music class with a music specialist. This experience gave me even more drive and curiosity to further discover the use of digital technologies in

elementary music education. I want to explore the idea of digital technology in elementary school music classrooms and the advantages and disadvantages it has on student learning. Digital technology is a fast developing idea that children are well aware of and often quite fluent in. My goal is to find out if digital technology is helping to promote learning the music curriculum in an active and interactive environment or if it is hindering their learning in any way.

In my inquiry I would like to find out what digital programs or tools are out there to assist with learning the various musical concepts in elementary music curriculum, as well as how digital technology in music curriculum is used to keep the children engaged in their learning.

\section{Background}

While inquiring about digital technologies used in elementary music classrooms I was able to find six different sources that I believe will have great assistance in my educational inquiry. The first source is an article by David Beckstead (2001) that describes the importance of 
giving students more freedom to explore music through the use of technology. This gives knowledge to the idea of learning traditional music composition through using various technologies and the impact that it can have on students' learning .

The next source is PDF surrounding the idea of students already being fluent in digital language and how the use of these new technologies can aid in their learning and understanding of music curriculum (Berk, n.d.). The understanding of what technologies students are already fluent in will assist us with creating appropriate lesson plans that will not only support individualized learning for students but will also promote further learning and the want to learn more outside of the classroom.

Next useful resource that I will be using in my research is a lesson log created by Eugene Cantera. This log deals with the importance of creating a sense of classroom community through the use of technology in music. Cantera (2012) explains how using technology in music can encourage learners to learn in new and exciting ways .

While searching for appropriate resources I explored many videos on YouTube. The first video I explored showed examples of students interacting with the smart board during the teacher's lesson. The benefits of digital technology in learning musical concepts is discussed. The teacher provides ideas of games that can be used for any elementary school grade level in music classes (ISD279, 2012).

My fourth resource was written by Dr. Heikki Ruismäki and Dr. Antti Juvonen (2009). It suggests the fact that technology supports musical learning and can make learning easier and more meaningful. It can assist with the creation of a well-rounded curriculum, create new challenges for both the teacher and students to find solutions to and supports the idea of informal learning and student exploration in the area of music education . 
My last resource is another YouTube video. In this video a teacher discusses the various online resources that supports the learning of music curriculum and creative learning. She shows that there are resources for every section of curriculum taught in music. Examples given were Brain Pop, Animoto and Compose. These are great resources for individualized learning and working together with peers (Dudley, 2010).

These various articles, papers, lesson logs and online videos provided me with a good introduction to the various ways that digital technologies are used in elementary music education, and in some cases how they have made an impact in student learning. From here I conducted my own research study to further investigate my inquiry of the various technologies that are being used in music classes and, the positive and negative elements of using digital technology within music classrooms.

\section{Research Context}

In my search for research data I was able to collect information from the Understanding Current and Emerging Pedagogical Technologies class, home, karaoke bars, school placements and other faculties in the university. These are the types of people I collected data from: education students, university professors, current and previous mentor teachers, friends and family, and people who work with children in or out of music programs. I had 10 people complete my online survey which I created in Google Forms, I did one in person interview and had two email interview responses in which I gathered my data from.

To ensure no risk to my participants before starting my research I took the TCPS 2: Core online learning course on how to conduct research professionally and ethically. By completing this course I received a Government of Canada Certificate that states I am allowed to conduct research. After this course was completed I created an online survey that I sent out to our Understanding Current and Emerging Pedagogical Technologies class. This survey was 
completely anonymous so people would not be singled out in their answers. I also sent this survey out to my friends and family and posted it on Facebook so that people who were interested and may not be a close friend of mine had the opportunity to help me out in my inquiry. I conducted an in-person interview and a couple email interviews to collect data from subject matter experts (music specialists) and ensured that they knew that any information provided would be kept anonymous within my research findings.

\section{Methods of Investigation}

The methods of data collection that I utilized were online surveys, email interviews, and in-person interviews. After collecting the data I analyzed it through the use of graphs created by Google surveys, Wordles, and transcriptions of interviews that I have recorded and received through email. I organized my data by categorizing the various findings so that I can see what amount of the findings would be advantages to using technology in music education and what amount of the findings state technology as a disadvantage to teaching curriculum. I also uses\d graphs and wordles created from the collected data to represent all of the findings throughout my inquiry.

\section{Findings}

My investigation in regards to music education did not provide me with as many results as I was originally hoping for. I believe that even though my survey was sent out to the whole class, some students may have felt intimidated by the fact that they do not have experience or backgrounds in music education. The most valuable information was given through two participants of my online survey that were elementary school teachers and had backgrounds in music and my in person interview of a Mount Royal University faculty member. A summary of my various findings to the answers I asked in my survey and interviews can be found below. 
My research began with an anonymous online survey. The responses that came back were slightly limited, but they still provided me with some very pertinent information in regards to my inquiry. I thought that it was important to know the demographics of the survey participants; this would assist me figuring out which participants work in the field and which ones were giving feedback based on personal experience or inferences they may have had.

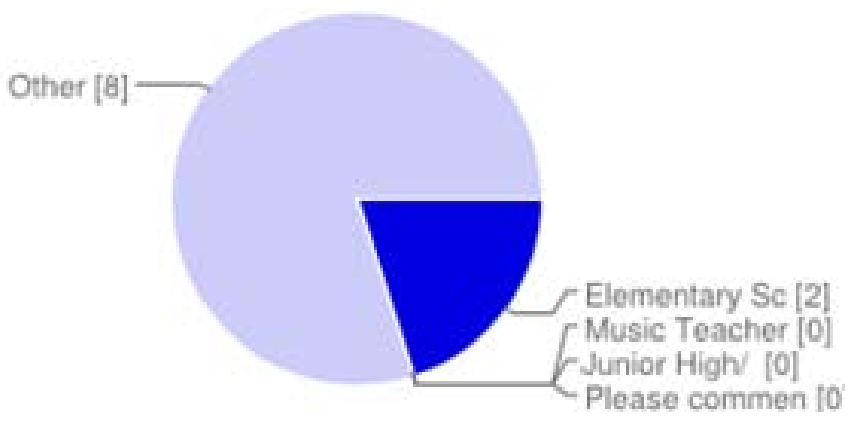

Figure 1. Demographic of Participants

I was able to get information from a few teachers (one being a music specialist), as well as eight "others" who let me know what their "title" was. I got responses from people who sing, teach music, work with students in other areas of education and some that just love music (have a passion for it like myself). This idea was very important and lead me to choose people who I found appropriate to further interview to see if they had any other further insight into my inquiry. After discovering the demographics of my survey I wanted to figure out what types of digital technologies are being used in music classes right now. I got a bunch of responses, some expected and some unexpected. The tools that are being used that I was already aware of are things like SMART boards, computers, keyboards, IPods/IPads, and sound recording equipment. Some that surprised me were tools like music softwares, online composing programs, electronic instruments, music engineering equipment and google docs (survey participants 5\&8). 


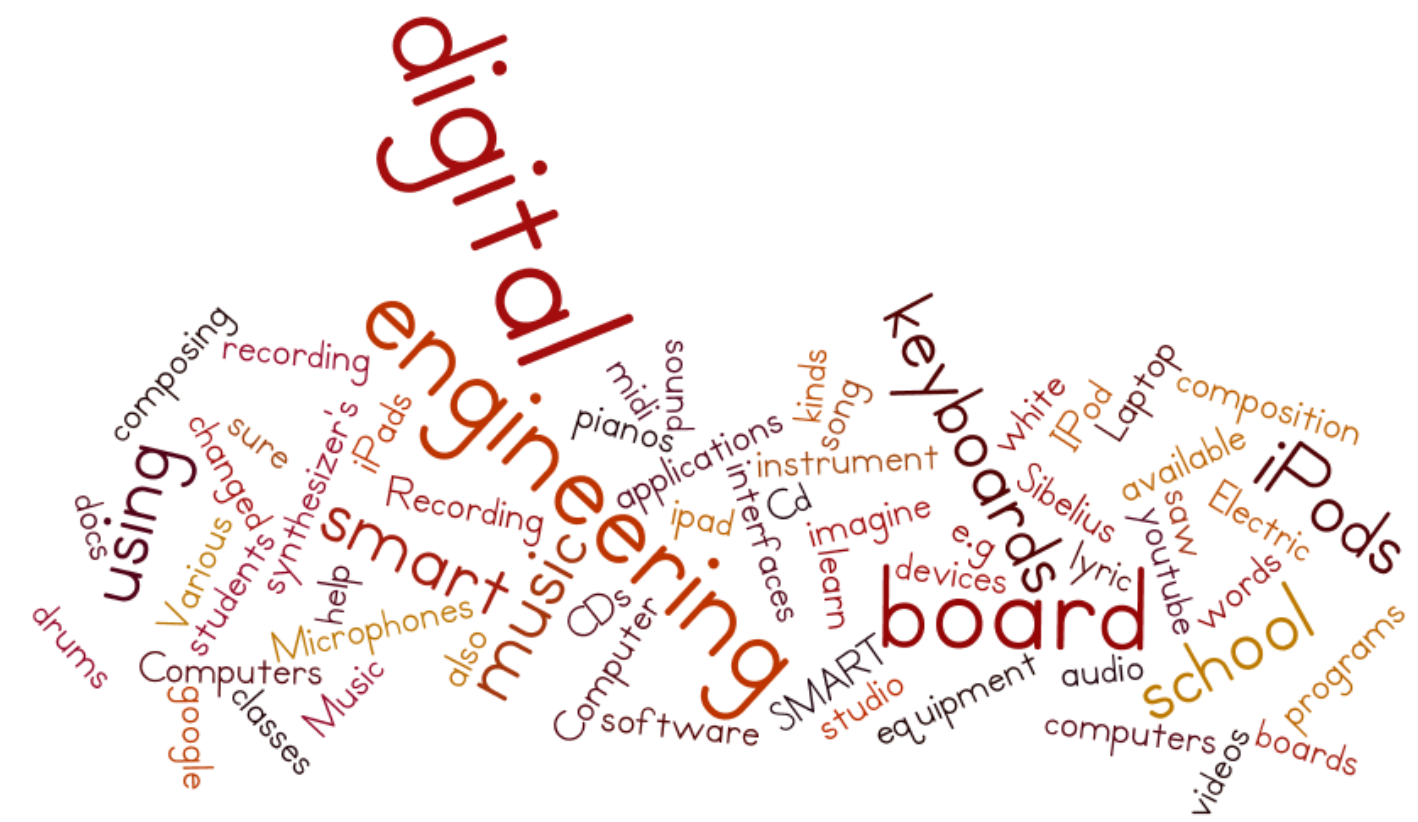

Figure 2. Types of digital technologies in music classes

When discussing digital technologies that are being used in music classes, I can look back through my initial background sources. While viewing the YouTube videos I was provided with various online programs that can support the idea of active and engaged learning in the music curriculum. Tools like Sibelius and Garage Band can be used to compose music and teach students about instruments that work well together to create great melodies and harmonies. The programs teach children about basic music components in relation to composition and provide a good opportunity for both individual and group projects (Dudley, 2010). The other video that compliments my inquiry showed and discussed how to integrate technology to promote active learning in music classes. It shows the SMART board's ability to be a very interactive tool that complements the learning and understanding the basic musical concepts that must be taught in elementary music curriculum (ISD279, 2012).

After discovering and learning about the various types of technologies that could be used 
in music education I needed to figure out what the advantages of using technology in music education were.

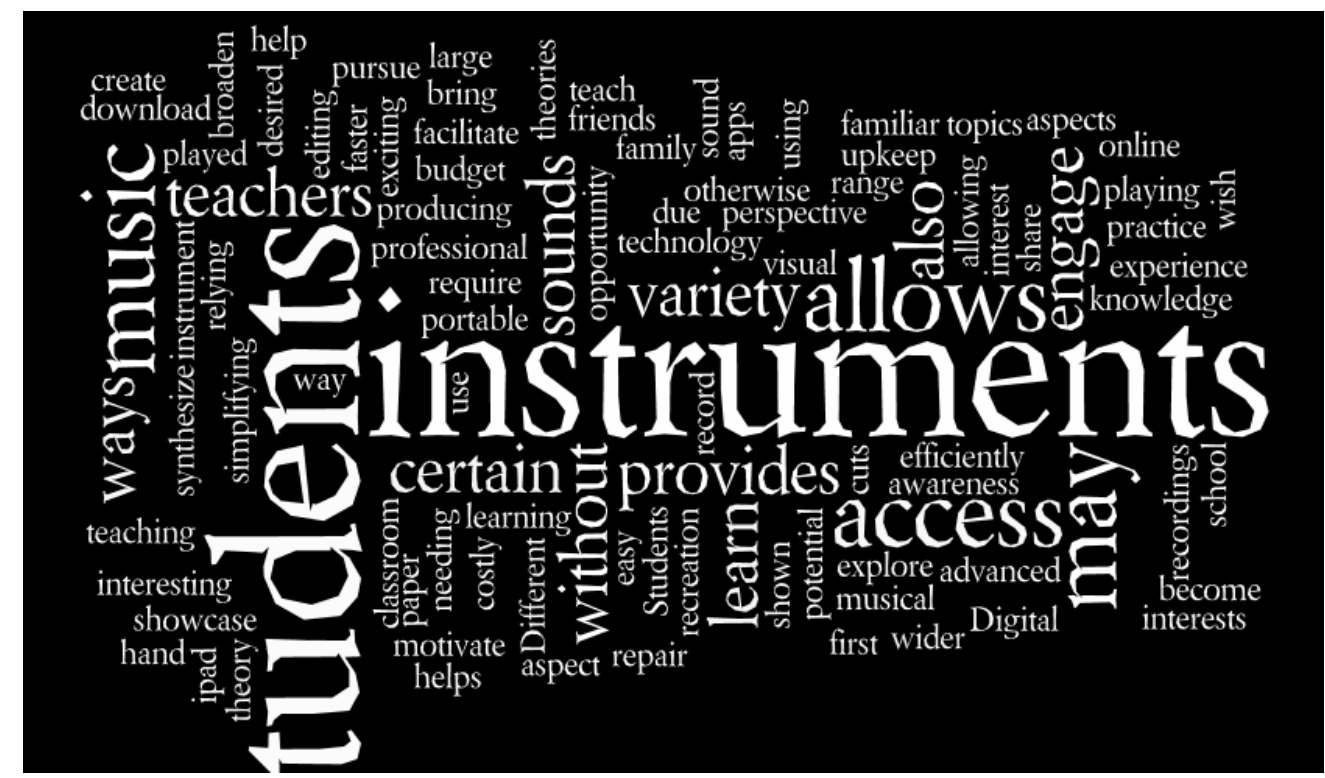

Figure 3. The pros of digital technology in music education.

The responses from my survey created an understanding of technology being used to support student engagement in their learning. One survey participant believed that digital technologies provide students with multiple ways of learning the same material which in return can support students with different learning styles (survey participant 2). This idea allows for individual creativity (especially in the higher elementary grades - those who are learning to compose their own music) and exploration in a different way. It also gives teachers a new way to facilitate learning in interesting and exciting ways.

Since my inquiry is a general inquiry into the use of technology in music education I also had to explore the negative sides of using digital technology in music education. I was extremely shocked to find out that most people (especially music teachers) still believe that the more traditional ways of teaching music is more beneficial to student learning. Some of the survey 
answers stated that technology can take up too much time from student learning (survey participant 6). Schools may not have enough resources to provide computers for all students to use at the same time for music purposes (survey participant 7). Technology can be unreliable and may take attention away from the teacher who is trying to conduct a lesson on a new musical concept (survey participant 2). Another valid point presented to me in my findings was the idea that to teach music to students the teacher needs space and technology can take up the space that the children could be moving around in and exploring music through body movement (interview participant 1). One answer that I found very intriguing was the idea that technology can take the "soul” out of music. The synthesized sounds can take the emotion that playing a musical instrument can provide to an individual. It can create a great disconnect between music and an individual (survey participant 4).

The final question that I posed in my survey attempted to bring a positive spin back on the use of technology in music classes and how it enhances the learning process.

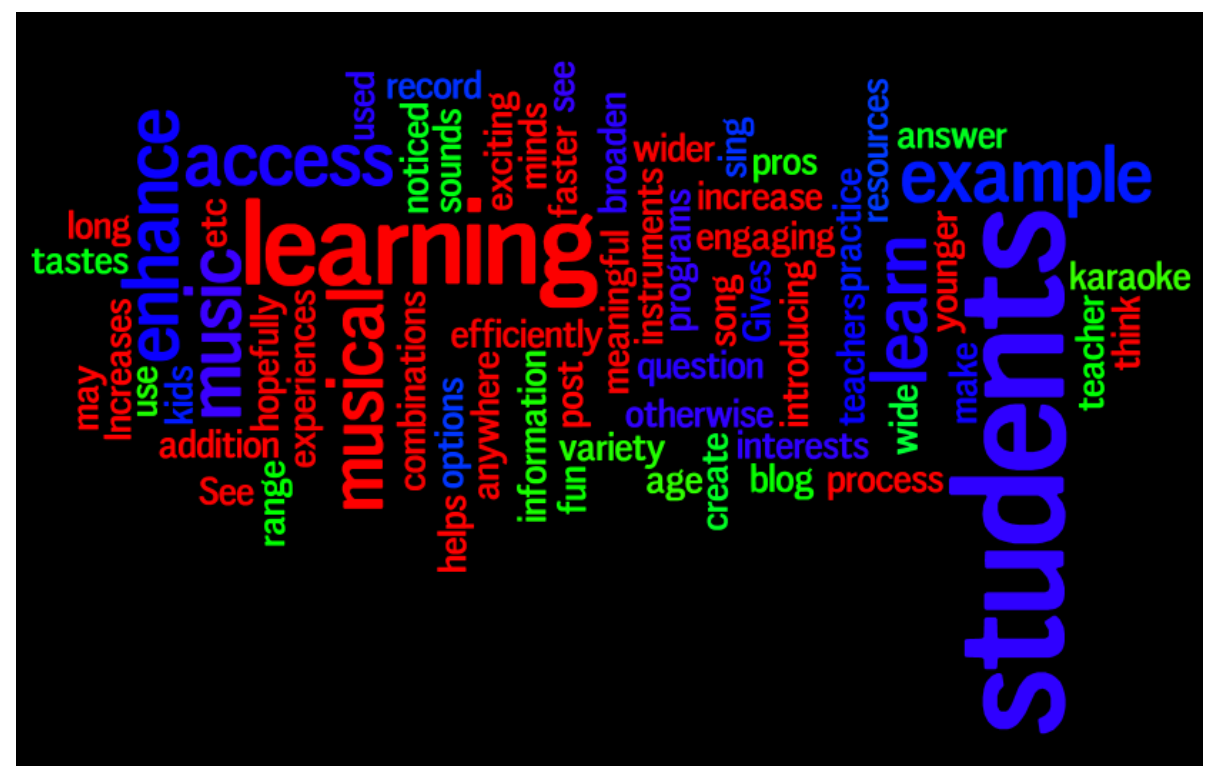

Figure 4. How technology can enhance the learning process in music education. 
My survey helped me to understand that although people may not think technology is beneficial when it comes to teaching elementary music curriculum, they do agree that if it is used it would promote an engaging environment for active learning. It can provide opportunities for online communication through blogs and videos which can be exciting for young learners.

Digital technology can greatly increase the amount of resources that a teacher and their students can use when it comes to creative learning projects and group assignments. And if the students are having fun in their classes it can create a meaningful experience in their learning.

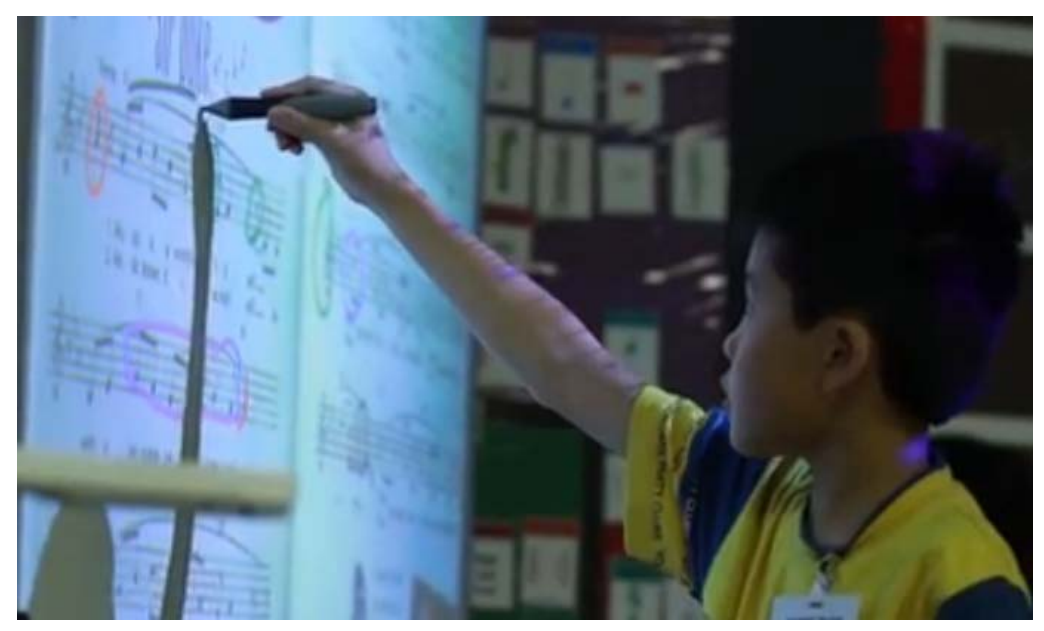

Figure 6. Interactive learning with a SMART board (ISD279, 2012).

I also asked for advice that could assist me as a future teacher in regards to integrating/using technology in elementary music education. The ideas that stood out most to me was to have balance between using technology and traditional ways of learning (survey participant 1). If I were to choose to use technology I must make sure that the technology does not take away from the student's learning because it is unreliable or confusing and I should not use digital technology just for the sake of using it (interview participant 1). If a teacher is unable to integrate it and use it with traditional ways of teaching then they should not be using technology to teach music. Technology can create distraction so if you cannot use it in a way that controls the class it is more of a hindrance. 


\section{Conclusions and Recommendations}

Through this inquiry I was able to discover the various technologies that are being used in elementary classrooms and music classrooms. I was able to get opinions from various people who took my survey or allowed me to interview them. They provided insight into the pros and cons of using digital technology in elementary music education and the majority of them came to a conclusion that digital technologies could take away from the learning process in music classes. The reasons for this are that technology takes up space in the classroom, takes up time because it is not always reliable and it can take away the authenticity that gets created through exploring instruments within the classroom. Although the inquiry showed that technology may be a distraction in a music class I believe that if it is used properly and is balanced with traditional teaching methods it can provide a more unique and engaging experience for the students. I believe that technology can be used as long as it does not take away from student learning.

What I found most intriguing in my findings was the idea that technology can take away the authenticity of music in the classroom. I took a long time to think about what this meant and realized that if my elementary music teacher would not have had us exploring types of music through touch, listening and moving that I would not have the passion for music that I have today.

Even though I will most likely not be an elementary music teacher, this inquiry has validity and can be transferred over to other subjects as well. The common theme that runs across all disciplines with respect to digital technology in the classroom is the idea of balance. If I can become fluent in the various digital technologies that help promote active and engaged learning in the classroom I can work on creating that balance that will promote as much learning 
as possible every day.

If I were to delve further into this inquiry I would ask a few more questions that I believe would provide more information for this particular topic.

1) How would you rank music education importance to other subjects taught in school?

2) On a scale of 1-10 how would you rate the importance of elementary music education?

3) Why do teachers still believe that a traditional way of teaching music is more valuable when teaching the elementary school music program?

\section{References}

Beckstead, D. (2001). Will Technology Transform Music Education?: Although technological advances make composing easier, music educators tend to use these tools to make traditional methods more accessible rather than explore new possibilities in composing. Music Educators Journal, 87(6), 44-49. Retrieved September 11, 2014, from http://mej.sagepub.com/content/87/6/44.citation

doi: $10.2307 / 3399692$

Berk, R. (n.d.). Use of Technology and Music to Improve Learning. Retrieved from http://images.pearsonassessments.com/images/NES_Publications/2008_12Berk_13012_1 . pdf

Cantera, E. (2012, September 18), Technology in Music-Lesson Logs. Retrieved September 11, 2014, from http://www.lessonlogs.com/technology-in-music-education/

Dudly, S. (2011, March 7). Incorporating Music into Technology [Video file]. Retrieved September 11, 2014, from https://www.youtube.com/watch?v=DHhmvu01Myo 
ISD279. (2012, October 4). Learning with Technology in Music Education [videofile].

Retrieved September 11, 2014, from

https://www.youtube.com/watch?v=9MkSAJYnO3Y

Juvonen, A., \& Ruismäki, H. (2009). The New Horizons for Music Technology in Music

Education. Retrieved from

http://www.mv.helsinki.fi/home/hruismak/julkaisut_files/The_new_horizonts_for_music

technology.pdf 